Secretome profiling of oral squamous cell

carcinoma-associated fibroblasts reveals organization and disassembly of extracellular matrix and collagen metabolic process signatures

\title{
Bagordakis, Elizabete
}

2016-07

Bagordakis , E , Sawazaki-Calone , I, Soares Macedo , C C , Carnielli , C M , de Oliveira , C E , Rodrigues , P C , Rangel , A L C A , dos Santos , J N , Risteli , J , Graner , E , Salo , T , Paes Leme , A F \& Coletta, R D 2016 , ' Secretome profiling of oral squamous cell carcinoma-associated fibroblasts reveals organization and disassembly of extracellular matrix and collagen metabolic process signatures ', Tumor Biology , vol. 37 , no. 7 , pp. 9045-9057 . https://doi.org/10.1007/s13277-015-4629-y

http://hdl.handle.net/10138/225773

https://doi.org/10.1007/s13277-015-4629-y

publishedVersion

Downloaded from Helda, University of Helsinki institutional repository.

This is an electronic reprint of the original article.

This reprint may differ from the original in pagination and typographic detail.

Please cite the original version. 


\title{
Secretome profiling of oral squamous cell carcinoma-associated fibroblasts reveals organization and disassembly of extracellular matrix and collagen metabolic process signatures
}

\author{
Elizabete Bagordakis $^{1}$ - Iris Sawazaki-Calone ${ }^{2}$ - Carolina Carneiro Soares Macedo ${ }^{1}$. \\ Carolina M. Carnielli ${ }^{3}$ - Carine Ervolino de Oliveira ${ }^{1}$ - Priscila Campioni Rodrigues ${ }^{1}$. \\ Ana Lucia C. A. Rangel ${ }^{2}$. Jean Nunes dos Santos ${ }^{4} \cdot$ Juha Risteli $^{5,6}$ • Edgard Graner ${ }^{1}$ • \\ Tuula Salo ${ }^{5,6,7,8}$ • Adriana Franco Paes Leme ${ }^{3}$. Ricardo D. Coletta ${ }^{1}$
}

Received: 20 November 2015 / Accepted: 10 December 2015 /Published online: 13 January 2016

(C) International Society of Oncology and BioMarkers (ISOBM) 2016

\begin{abstract}
An important role has been attributed to cancerassociated fibroblasts (CAFs) in the tumorigenesis of oral squamous cell carcinoma (OSCC), the most common tumor of the oral cavity. Previous studies demonstrated that CAFsecreted molecules promote the proliferation and invasion of OSCC cells, inducing a more aggressive phenotype. In this study, we searched for differences in the secretome of CAFs and normal oral fibroblasts (NOF) using mass spectrometrybased proteomics and biological network analysis. Comparison of the secretome profiles revealed that upregulated proteins involved mainly in extracellular matrix organization and disassembly and collagen metabolism. Among the upregulated proteins were fibronectin type III domain-containing 1 (FNDC1), serpin peptidase inhibitor type 1 (SERPINE1), and stanniocalcin 2 (STC2), the upregulation of which was validated by quantitative PCR and ELISA in an independent set of CAF cell lines. The transition of transforming growth
\end{abstract}

Electronic supplementary material The online version of this article (doi:10.1007/s13277-015-4629-y) contains supplementary material, which is available to authorized users.

Adriana Franco Paes Leme adriana.paesleme@Inbio.cnpem.br

Ricardo D. Coletta coletta@fop.unicamp.br

1 Department of Oral Diagnosis, School of Dentistry, State University of Campinas, Av. Limeira 901, CEP 13414-018 Piracicaba, SP, Brazil

2 Oral Pathology and Oral Medicine, Dentistry School, Western Paraná State University, Cascavel, PR, Brazil factor beta 1 (TGF- $\beta 1$ )-mediating NOFs into CAFs was accompanied by significant upregulation of FNDC1, SERPINE1, and STC2, confirming the participation of these proteins in the CAF-derived secretome. Type I collagen, the main constituent of the connective tissue, was also associated with several upregulated biological processes. The immunoexpression of type I collagen $\mathrm{N}$-terminal propeptide (PINP) was significantly correlated in vivo with CAFs in the tumor front and was associated with significantly shortened survival of OSCC patients. Presence of CAFs in the tumor stroma was also an independent prognostic factor for OSCC disease-free survival. These results demonstrate the value of secretome profiling for evaluating the role of CAFs in the tumor microenvironment and identify potential novel therapeutic targets such as FNDC1, SERPINE1, and STC2. Furthermore, type I collagen expression by CAFs, represented by PINP levels, may be a prognostic marker of OSCC outcome.
3 Brazilian Biociences National Laboratory-CNPEM, CEP 13083-970 Campinas, SP, Brazil

4 Laboratory of Surgical Pathology, Dental School, Federal University of Bahia-UFBA, Salvador, BA, Brazil

5 Cancer and Translational Medicine Research Unit, University of Oulu, Oulu, Finland

6 Medical Research Center, Oulu University Hospital, Oulu, Finland

7 Oral and Maxillofacial Diseases Unit, University of Helsinki, Helsinki, Finland

8 Helsinki University Hospital, Helsinki, Finland 
Keywords Cancer-associated fibroblasts $\cdot$ Secretome Extracellular matrix · Type I collagen · FNDC1 - SERPINE1 · STC2

\section{Introduction}

Oral squamous cell carcinoma (OSCC) is the eleventh most common solid tumor worldwide, representing about $4 \%$ of all malignancies [1]. The World Health Organization (WHO) estimated for 2012 approximately 685,000 new cases of head and neck cancer, with the oral cavity as the most frequent site with 300,000 cases and 145,000 deaths [1]. Despite advances in research and treatment options, especially with new chemotherapy drugs, the prognosis of patients with OSCC has remained virtually unchanged over recent decades, remaining at $50 \%$ over 5 years [2]. This low survival rate is attributed mainly to late diagnosis, poor response to chemotherapy and radiotherapy, and insufficient biomarkers for early diagnosis and post-therapeutic monitoring [3].

During the process of invasion, tumor cells are able to induce a series of changes characterized by the accumulation of inflammatory and immune cells, blood and lymphatic capillaries, components of the extracellular matrix, fibroblasts, and myofibroblasts (also called cancer-associated fibroblasts (CAFs), comprising the tumor microenvironment [4]. There is evidence that all components of the tumor stroma can critically influence carcinogenesis and the malignant phenotype in multiple stages of tumor development $[5,6]$. Among these components, CAFs, fibroblast-like cells that acquire the ability to express isoform $\alpha$ of the smooth muscle actin ( $\alpha$-SMA) and synthesize an extensive repertoire of cytokines, growth factors, chemokines, hormones, neurotransmitters, inflammatory mediators, adhesion proteins, and most abundantly extracellular matrix proteins, have been highlighted as the major player in tumor-stroma cross talk [7].

CAFs contribute significantly to important hallmarks necessary for cancer progression such as invasion and metastasis, immune escape, inflammation, angiogenesis, and sustained growth [8-10]. The presence of these cells is also associated with poor prognosis in numerous tumor types, including OSCCs [11-17]. Identifying proteins synthesized by CAFs is crucial for a better understanding of the biological events associated with oral tumorigenesis and for the discovery of new tumor biomarkers, enabling, for example, discrimination of patients at high and low risk of developing metastasis and allowing for more individualized treatment. Previous studies have already identified proteins secreted by CAFs in colorectal $[18,19]$, head and neck cancer [20], and nasopharyngeal cancer [21]. In a previous study, we demonstrated that CAFs promote tumorigenesis of oral tongue SCC cell lines via secretion of high levels of activin A, a member of the transforming growth factor- $\beta$ superfamily of proteins [8].
CAFs also secrete various types of collagen, which may lead to tumor growth, invasion, and spread. Interestingly, the release of the N-terminal propeptide of type I collagen (PINP) was associated with the poor prognosis of oral tongue SCC patients [22].

Aiming to identify proteins released by CAFs, the present study compared the secretome derived from CAFs isolated from OSCCs with the secretome of fibroblasts isolated from normal oral mucosa. The expression levels of fibronectin type III domain-containing protein 1 (FNDC1), serpin peptidase inhibitor type 1 (SERPINE1, also called plasminogen activator inhibitor-1), and stanniocalcin 2 (STC2) in the CAF secretome were significantly higher, enhancing our understanding of the regulatory mechanisms of CAFs in the microenvironment of OSCCs. Biological processes associated with type I collagen expression were overrepresented in CAFs, and high immunoexpression levels of both PINP and $\alpha$-SMA (representing CAF density) in the tumor invasive front were associated with a worse prognosis for OSCC patients.

\section{Material and methods}

\section{Clinical samples and cell culture}

The study was approved by the Human Research Ethics Committee of the School of Dentistry, University of Campinas, Brazil (protocol number 090/2011). After informed consent was given, samples were taken from OSCC patients and from patients with healthy oral mucosa without history of exposure to risk factors related to OSCC, such as smoking and alcohol consumption. The patients (six males and one female) were diagnosed with OSCC with a histological grade of welldifferentiated (two cases) and moderately differentiated (five cases). Each tumor sample was obtained in the central area of the lesion, avoiding necrotic areas, and divided in two parts: One was fixed in formalin and embedded in paraffin for hematoxylin and eosin staining, while the other was washed with phosphate-buffered saline (PBS), incubated in Dulbecco's modified Eagle's media (DMEM, Invitrogen, USA) supplemented with $10 \%$ calf serum (Invitrogen, USA) and antibiotics, and immediately processed. Normal oral mucosa was obtained from four males and three females and processed the same way.

Normal oral fibroblast (NOF) and CAF cell lines were established using tissue explants and characterized as described previously [23]. The secretome was initially investigated by mass spectrometry analysis, and proteins showing a significantly higher expression in CAFs compared to NOFs were subsequently validated in an independent set of six NOF cell lines and six CAF cell lines. 


\section{Sample preparation for liquid chromatography associated with mass spectrometry}

One cell line of each group (NOF-1 and CAF-1) plated at $80 \%$ confluence (three $100-\mathrm{mm}^{2}$ dishes per condition per experiment) were gently washed with PBS and incubated in a serum-free media for $24 \mathrm{~h}$ at $37{ }^{\circ} \mathrm{C}$. After collection of the conditioned media, ethylenediaminetetraacetic acid (EDTA) and phenylmethylsulfonyl fluoride (PMSF) were added at a final concentration of $1 \mathrm{mM}$. Cell debris and intact cells were eliminated by centrifugation, and the conditioned media were concentrated using a $3000-\mathrm{Da}$ centrifugal filter (Amicon Ultra, Millipore, Ireland) at $4{ }^{\circ} \mathrm{C}$. Protein concentrations were determined using a protein assay according to the manufacturer's instructions (Bio-Rad Protein Assay, Bio-Rad, USA). Proteins $(80 \mu \mathrm{g})$ were treated with a final concentration of $1.6 \mathrm{M}$ urea, following reduction $(5 \mathrm{mM}$ dithiothreitol, $25 \mathrm{~min}$ at $\left.56{ }^{\circ} \mathrm{C}\right)$, alkylation $(14 \mathrm{mM}$ iodoacetamide, $30 \mathrm{~min}$ at room temperature in the dark), and digestion with trypsin (1:50, $w / w)$. The reaction was stopped with $1 \%$ trifluoroacetic acid (TFA) and desalted with Sep-Pack cartridges. The samples were dried in a vacuum concentrator, reconstituted in $0.1 \%$ formic acid, and analyzed by liquid chromatography associated with mass spectrometry (LCMS/MS). Three independent experiments were performed for each cell line.

\section{LC-MS/MS analysis}

An aliquot containing $3 \mu \mathrm{g}$ of proteins was analyzed on an ETD-enabled LTQ Orbitrap Velos Mass Spectrometer (Thermo Fisher Scientific, USA) connected to a nanoflow liquid chromatography column (LC-MS/MS) by an EASY-nLC System (Proxeon Biosystem) through a proxeon nanoelectrospray ion source. Peptides were separated by a $2-90 \%$ acetonitrile gradient in an analytical PicoFrit column $(20 \mathrm{~cm} \times$ id $75 \mu \mathrm{m}$, $5-\mu \mathrm{m}$ particle size, New Objective) at a flow of $300 \mathrm{nl} / \mathrm{min}$ over $212 \mathrm{~min}$. The nanoelectrospray voltage was set to $2.2 \mathrm{kV}$, and the source temperature was $275^{\circ} \mathrm{C}$. All instrument methods for the LTQ Orbitrap Velos were set up in the datadependent analysis (DDA) mode. The full-scan MS spectra $(\mathrm{m} / \mathrm{z} 300-1600)$ were acquired in the Orbitrap analyzer after accumulation to a target value of $1 \mathrm{e} 6$. The resolution in the Orbitrap was set to $r=60,000$. The 20 most intense peptide ions with charge states $\geq 2$ were sequentially isolated to a target value of 5000 and fragmented in the linear ion trap by lowenergy CID (normalized collision energy of $35 \%$ ). The signal threshold for triggering an MS/MS event was set to 1000 counts. Dynamic exclusion was enabled with an exclusion size list of 500, an exclusion duration of $60 \mathrm{~s}$, and a repeat count of 1 . An activation $q=0.25$ and an activation time of $10 \mathrm{~ms}$ were used.

\section{Protein identification and quantitative analysis}

The raw files were processed using the MaxQuant version 1.2.7.429, and the MS/MS spectra were searched using the Andromeda search engine against the Uniprot Human Protein Database (release July 11, 2012; 69,711 entries). The initial maximal allowed mass tolerance was set to $20 \mathrm{ppm}$ for precursor and then set to $6 \mathrm{ppm}$ in the main search and to $0.5 \mathrm{Da}$ for fragment ions. Enzyme specificity was set to trypsin with a maximum of two missed cleavages. Carbamidomethylation of cysteine (57.021464 Da) was set as a fixed modification, and oxidation of methionine (15.994915 Da) and protein $\mathrm{N}$ terminal acetylation $(42.010565 \mathrm{Da})$ were selected as variable modifications. The minimum peptide length was set to 6 amino acids. Bioinformatic analyses were performed using Perseus v.1.2.7.4,29, which is available in the MaxQuant environment. First, reverse and contaminant entries were excluded from further analysis. Label-free quantification was performed using the normalized spectral protein intensity (LFQ intensity). Data obtained from three independent experiments from each cell line were annotated, and for the analysis of differentially expressed proteins, the data were converted into $\log 2$ and Student's $t$ test was applied.

\section{Quantitative PCR}

Quantitative PCR (qPCR) was used for validation of six proteins identified in the LC-MS/MS with significantly higher levels (more than twofold) in CAF-1 cells compared to NOF-1 cells. Total RNA was isolated with the RNeasy mini kit (Qiagen, USA) according to the manufacturer's protocols. Following DNase I treatment, in order to eliminate genomic DNA contamination, $1 \mu \mathrm{g}$ of total RNA per sample was used to generate complementary DNA (cDNA) using Oligo-dT (Invitrogen, USA) and a superscript enzyme (Superscript II RT enzyme, Invitrogen, USA). The resulting cDNAs were subjected to qPCR using SYBR Green PCR Master Mix (Applied Biosystems, USA) in the StepOnePlus Real-Time PCR System (Applied Biosystems, USA). Gene expression was determined using the delta-delta CT method, and the housekeeping gene PPIA (cyclophilin A) was used as reference gene for data normalization. All reactions were performed in triplicate. Pairs of primers are described in Supplementary Table 1.

\section{Enzyme-linked immunosorbent assay}

The production of the proteins validated in the $\mathrm{qPCR}$ (FNDC1, SERPINE1 and STC2) as significantly higher in CAFs compared to NOFs were also assessed by enzymelinked immunosorbent assay (ELISA). To obtain conditioned cell culture media, cells were plated in 24-well culture plates at a density of 80,000 cells/well in DMEM containing $10 \%$ of 
calf serum. After $24 \mathrm{~h}$, the cells were rinsed with PBS and the media replaced by DMEM without serum. After another $24 \mathrm{~h}$, the media of each well was collected and concentrated using a 3000-Da centrifugal filter (Sartorius Stedim Biotech, Germany). Levels of SERPINE1 were analyzed with a human ELISA Kit SimpleStep (Abcam, USA) according to the manufacturer's protocol. For FNDC1 and STC2, plates were coated with the concentrated samples for $2 \mathrm{~h}$ at room temperature and non-specific binding sites were blocked with $3 \% \mathrm{BSA}$ in PBS for $2 \mathrm{~h}$. After washing, anti-FNDC1 antibody (clone Y12, Santa Cruz Biotechnology, USA), diluted 1:3000, and anti-STC2 antibody (Abcam, USA), diluted 1:1000, were added to the wells and incubated for $2 \mathrm{~h}$. After washing step, donkey anti-goat IgG horseradish peroxidase (HRP)-conjugated (Santa Cruz Biotechnology, USA), diluted 1:5000 (for FNDC1), and goat anti-rabbit IgG conjugated to HRP (Abcam, USA), diluted 1:10,000 (for STC2), were added and maintained for $1 \mathrm{~h}$. The reactions were developed with TMB substrate reagent set BD OptEIA (Becton Dickinson) according to the manufacturer's protocol. After terminating the reaction with $2 \mathrm{~N} \mathrm{H}_{2} \mathrm{SO}_{4}$, absorbance was read at $450 \mathrm{~nm}$ with correction at $650 \mathrm{~nm}$. Standard curves were constructed for FNDC1 (Santa Cruz Biotechnology, USA), ranging from 62.5 to $2000 \mathrm{pg} / \mathrm{ml}$, and STC2 (Abcam, USA), ranging from 0.37 to $46.88 \mathrm{pg} / \mathrm{ml}$. The wells of replicate plates were treated in a similar manner and used for cell counts. Cells were harvested using $0.2 \%$ trypsin and counted with a cell counter (Countess Automated Cell Counter, Invitrogen, USA). The values were expressed as nanograms of protein per cell.

\section{Treatment of NOF with TGF- $\beta 1$}

Lyophilized transforming growth factor beta 1 (TGF- $\beta 1$ ) (R\&D Systems, USA) was dissolved in culture media, aliquoted, and stored at $-80{ }^{\circ} \mathrm{C}$. To assess the effect of this cytokine, NOF cell lines were cultured in $0.1 \%$ of calf serum media containing $10 \mathrm{ng} / \mathrm{ml}$ of TGF- $\beta 1$ for $48 \mathrm{~h}$ [24].

\section{Immunohistochemistry}

Immunohistochemical analysis was performed in a cohort composed of 113 patients with primary OSCC, who were diagnosed and treated at two reference hospitals in Cascavel, state of Paraná, Brazil: the Oncology Center of Cascavel (CEONC, $n=46$ patients) and the UOPECCAN Cancer Hospital ( $n=67$ patients) from 1998 to 2008. The clinicopathological features of this cohort were recently described [25].

PINP and $\alpha$-SMA immunostaining was performed using the streptavidin-biotin peroxidase complex method. Briefly, after dewaxing and hydration in graded alcohol solutions, the sections were treated with $3 \% \mathrm{H}_{2} \mathrm{O}_{2}$ followed by antigen retrieval with $10 \mathrm{mM}$ citric acid $\mathrm{pH} 6.0$ in a pressure cooker.
After washing with PBS, the sections were treated with $1 \%$ bovine serum albumin (BSA) in PBS for $1 \mathrm{~h}$ and then incubated with polyclonal rabbit anti-human antibody against PINP [26], diluted 1:5000, or monoclonal mouse anti-human antibody against $\alpha$-SMA (clone 1A4, Dako, USA). Reactions were developed by incubating the sections with $0.6 \mathrm{mg} / \mathrm{ml} \mathrm{3}$, 3'-diaminobenzidine tetrahydrochloride (Sigma-Aldrich, USA) containing $0.01 \% \mathrm{H}_{2} \mathrm{O}_{2}$. Control reactions were performed by omission of the primary antibody.

$\alpha$-SMA-positive cells (CAFs) were assessed as described by Kellermann et al. [11]. Tumors lacking $\alpha$-SMA-positive cells were classified as negative, scanty if more than $1 \%$ and less than $50 \%$ of the stromal cells were $\alpha$-SMA positives, and abundant if more than $50 \%$ of the stromal cells were $\alpha$-SMApositive cells. The percentage of PINP-positive cells in the stromal cells in both the stroma within the tumor (designed overall area for the purposes of this study) and the deep invasive tumor front (defined as tumor front, which represents the band of tissue between the invasive tumor front and adjacent normal tissue) were scored as low (negative samples and samples up to $50 \%$ of positive cells) and high (more than $50 \%$ of positive cells) expression.

\section{Statistical analysis}

All in vitro assays were performed at least three times. For those assays, Mann-Whitney $U$ test or one-way analysis of variance (ANOVA) with post hoc comparisons based on the Tukey's multiple comparison test were applied, and the $p$ value of 0.05 was set as statistically significant.

For statistical purposes, samples classified as negative or scanty density of CAFs were grouped together and compared with samples with abundant presence of CAFs. Correlations between clinicopathological parameters of the tumors and immunohistochemical analyses were performed using Spearman's rank correlation. Survival curves were constructed based on the Kaplan-Meier method and compared with the log-rank test. For multivariate survival analysis, the Cox proportional hazard model with a stepwise method was employed.

\section{Results}

To characterize NOF and CAF cell lines, $\alpha$-SMA expression was assessed by qPCR. In this specific analysis, we used a pool of seven NOFs as a reference. All CAF cell lines showed at least a twofold increase in $\alpha$-SMA messenger RNA (mRNA) levels compared to the reference pool (Fig. 1a). Immunocytochemical analysis demonstrated strong cytoplasmic staining for $\alpha$-SMA in the CAF cell lines, which was not observed in the NOF cells (Fig. 1b). Immunoreactivity for vimentin was detected in $100 \%$ of both NOF and CAF cells, 


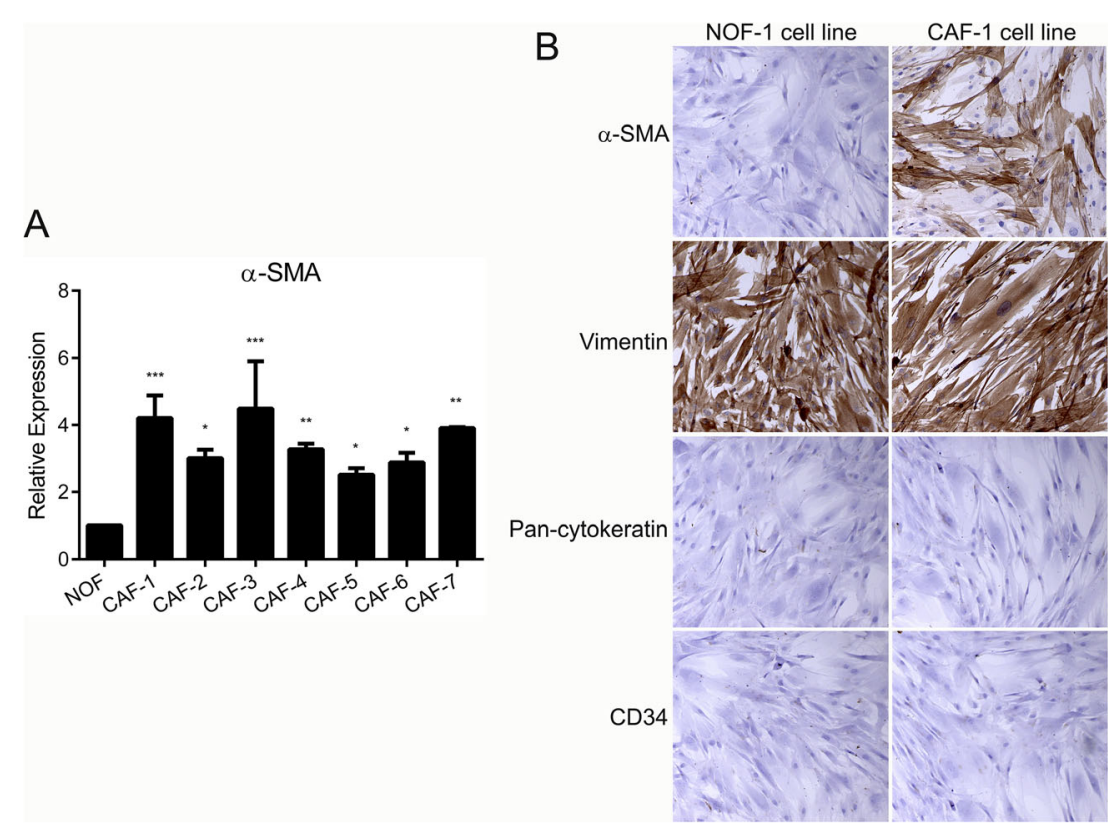

Fig. 1 Characterization of CAF cell lines. a The levels of $\alpha$-SMA mRNA in CAF and NOF cell lines were assessed by quantitative PCR. For comparison, expression in CAFs was normalized to the average value of the NOF cells. Data showed a clear overexpression above twofold in all CAF cell lines. b Immunocytochemistry analysis of markers of cell differentiation. CAFs demonstrated a vivid cytoplasmatic staining for

whereas cells were negative for pan-cytokeratin and CD34 marker (Fig. 1b).

Secreted proteins were collected from one NOF (NOF-1) and one $\mathrm{CAF}$ (CAF-1) cell line, digested with trypsin, and the resulting peptides were analyzed in independent triplicates via LC-MS/MS. Using normalized spectral protein intensity (LFQ intensity) in the MaxQuant software, accepting only peptide and protein identifications with an FDR better than 0.01, we identified 271 proteins (Supplementary Table 2). The $\log 2$ values of the expressed proteins were normalized by $Z$-score and represented in the heat map, which grouped the triplicates of each cell line together (Fig. 2). Combining Student's $t$ test and a fold-change of 2, applied in $\log 2$ LFQ intensity values, we identified 13 upregulated and 5 downregulated proteins in CAF cells (Table 1).

Functional annotation analysis of proteins identified in the two cell types was performed using all differentially expressed proteins (Supplementary Table 3). For that purpose, we used the ClueGO plugin v2.0.6 within Cytoscape v.3.0.1 for enrichment analysis and classified the proteins according to GO terms for biological processes and cellular components. The most significantly CAF overrepresented GO terms were extracellular matrix organization (GO 0030198, corrected $p$ value $=3.21 \mathrm{E}-37)$, extracellular matrix disassembly $(\mathrm{GO}$ 0022617 , corrected $p$ value $=1.31 \mathrm{E}-17)$, and collagen metabolic process (GO 0032963, corrected $p$ value $=2.19 \mathrm{E}-8$ ). In this context, we were able to relate those proteins that were found to be most significantly overrepresented in CAFs in
$\alpha$-SMA, which was not observed in NOFs. Immunoreactivity for vimentin was detected in both NOF and CAF cells, and both cells were negative to pan-cytokeratin and CD34. Representative images of one NOF (NOF-1) and one CAF (CAF-1) cell lines are shown here (original magnification $\times 100$ )

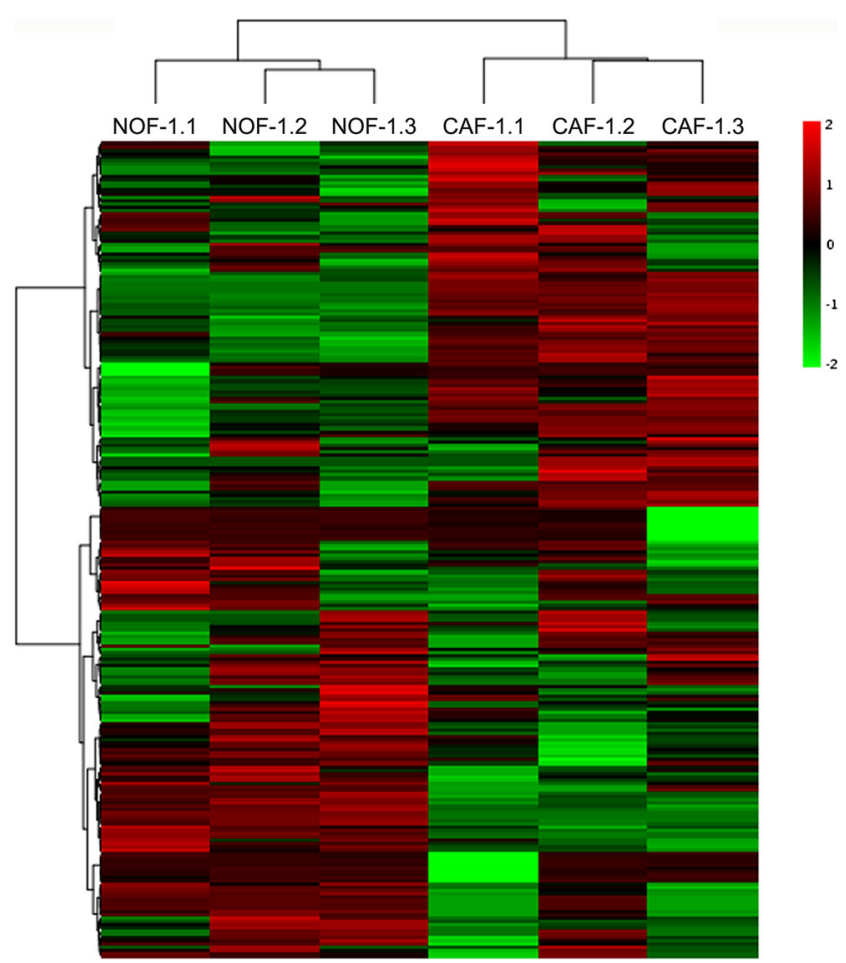

Fig. 2 Heat map of the differentially expressed proteins in NOF and CAF cells. Proteins identified in NOF-1 and CAF-1 cell lines were hierarchically clustered by using the $Z$-score LFQ values with MaxQuant software. This cluster analysis revealed clear differences between NOF and CAF cells 
Table 1 Upregulated and downregulated proteins identified in the secretome of CAFs

\begin{tabular}{|c|c|c|c|c|}
\hline & Protein & Abbreviation & Ratio & $p$ Value \\
\hline \multirow[t]{13}{*}{ Upregulated } & Fibronectin type III domain-containing protein 1 & FNDC1 & 4.83 & 0.0001 \\
\hline & Insulin-like growth factor-binding protein 3 & IGFBP3 & 4.82 & 0.0003 \\
\hline & Cartilage oligomeric matrix protein & COMP & 4.57 & 0.0012 \\
\hline & Elastin & ELN & 3.54 & 0.007 \\
\hline & Collagen alpha-1(VII) chain & COL7A1 & 3.35 & 0.006 \\
\hline & Stromelysin-1 & MMP3 & 3.23 & 0.0002 \\
\hline & Transforming growth factor-beta-induced protein ig-h3 & TGFBI & 2.97 & 0.002 \\
\hline & Plasminogen activator inhibitor 1 & SERPINE1 & 2.59 & 0.0006 \\
\hline & Xylosyltransferase 1 & XYLT1 & 2.53 & 0.011 \\
\hline & Collagen alpha-1(V) chain & COL5A1 & 2.39 & 0.002 \\
\hline & Stanniocalcin-2 & STC2 & 2.39 & 0.005 \\
\hline & Latent-transforming growth factor beta-binding protein 2 & LTBP2 & 2.28 & 0.001 \\
\hline & Procollagen-lysine, 2-oxoglutarate 5-dioxygenase 2 & PLOD2 & 2.13 & 0.003 \\
\hline \multirow[t]{5}{*}{ Downregulated } & Tetranectin & CLEC3B & -5.23 & 0.0004 \\
\hline & Ectonucleotide pyrophosphatase/phosphodiesterase family member 2 & ENPP2 & -4.75 & 0.001 \\
\hline & Collagen alpha-1(XIV) chain & COL14A1 & -3.43 & 0.002 \\
\hline & Insulin-like growth factor-binding protein 5 & IGFBP5 & -3.20 & 0.009 \\
\hline & Laminin subunit beta- 2 & LAMB2 & -2.17 & 0.0008 \\
\hline
\end{tabular}

Values represent the fold of expression in CAFs in relation to NOFs

comparison with NOF cells, including FNDC1, SERPINE1, STC2, elastin (ELN), matrix metallopeptidase 3 (MMP3), and xylosyltransferase 1 (XYLT1), to extracellular matrix organization and disassembly.

To confirm the higher expression of those six proteins in CAFs compared to NOFs, we performed qPCR analysis followed by ELISA. A consistent and significant overexpression of FNDC1, SERPINE1, and STC2 was observed across the different CAF cell lines compared to controls (difference between groups $p=0.01$ for FNDC1, $p=0.0006$ for SERPINE1, $p=0.001$ for STC2), whereas overexpression of ELN, MMP-3, and XYLT1 was identified in a few CAF cell lines, revealing no significant differences between groups (Fig. 3). In this specific analysis, we used a pool of six NOFs as a reference. Significantly higher levels of FNDC1 $(p=0.01)$, SERPINE1 $(p=0.005)$, and STC2 $(p=0.02)$ were also observed in CAFs compared to NOFs in the ELISA (Fig. 4). Stimulation of NOF cell lines with TGF- $\beta 1$ was performed to induce CAF activation as previously described [24]. Treatment with TGF- $\beta 1$ significantly induced the expression of $\alpha$-SMA (Supplementary Fig. 1), which was followed by significant upregulation of FNDC1, SERPINE1, and STC2 (Fig. 5).

Several biological processes overrepresented in CAFs were associated with collagen anabolism and catabolism. Thus, to further evaluate the relevance of type collagen I expression originating from CAFs to OSCC, immunohistochemical analysis of both $\alpha$-SMA, characterizing CAFs, and PINP was performed. Immunohistochemical reaction for $\alpha$-SMA showed CAF-positive cells in $91.4 \%$ of OSCCs. CAFs were located in close contact with neoplastic islands, and areas of tumor-free stroma demonstrated a complete lack of CAFs. All samples demonstrated positivity for $\alpha$-SMA in the smooth muscle of the blood vessel walls, which worked as an internal positive control. Interestingly, PINP was observed as a cytoplasmic stain with variable distribution and intensity in both tumor and stromal cells. Many CAF cells were reactive for the antibody anti-PINP (Fig. 6), and a significant correlation between CAF density and PINP expression in the invasive front was detected (Table 2). The clinicopathological correlations with the presence of CAFs and the expression of PINP in the stromal cells are depicted in Table 3. A significant correlation between PINP immunoexpression in the overall tumor stroma and age was observed in this cohort $(p=0.002)$. Significant correlations were also observed between the density of CAFs in the overall stroma $(p=0.007)$ and invasive front stroma $(p=0.003)$ and type of treatment and between the presence of CAFs in the invasive front and the development of a second primary tumor $(p=0.05)$.

Increased PINP expression by stromal cells in both overall stroma $(p=0.005)$ and invasive front $(p=0.005)$ was associated with shortened specific survival (Fig. 7). Abundant presence of CAFs in the invasive front was also significantly associated with lower specific survival ( $p=0.006$, Fig. 7). Patients whose tumors showed high expression of PINP in the stromal cells in the invasive front had a significantly shorter disease-free survival period than patients with low expression 
Fig. 3 FNDC1, SERPINE1, and STC2 are overexpressed in CAF cell lines. Expression analysis of FNDC1, ELN, SERPINE1,

MMP-3, XYLT1, and STC2,

which were identified in the LC-

MS/MS with significantly higher

levels (more than twofold) in

CAF-1 cells compared to NOF-1

cells, were verified by

quantitative PCR in six different

cell lines of NOF and six of

CAFs. Higher levels of FNDC1,

SERPINE1, and STC2 were

observed across the different $\mathrm{CAF}$

cell lines compared to control.

ELN, MMP-3, and XYLT1

overexpressions were not

confirmed in this set of CAFs.

${ }^{*} p<0.05,{ }^{*} p<0.01$,

$* * * p<0.005, * * * * p<0.001$
A

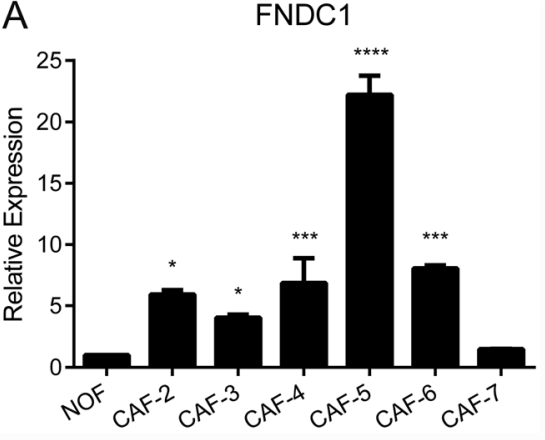

C

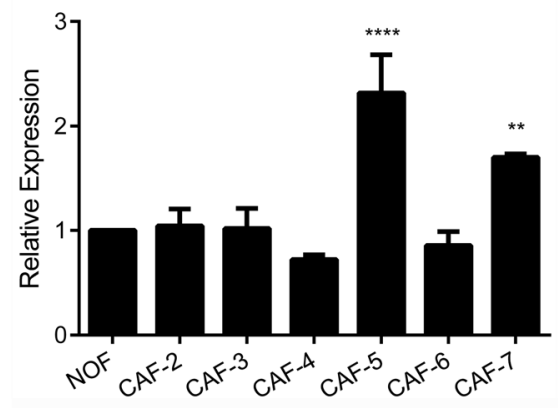

E

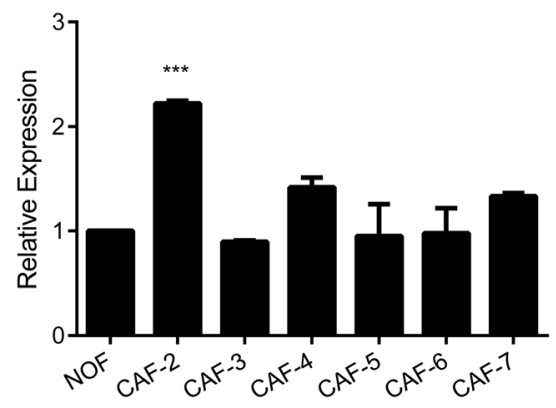

B ELN

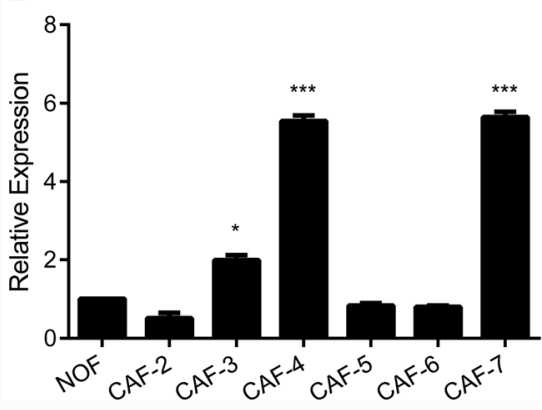

D

SERPINE1

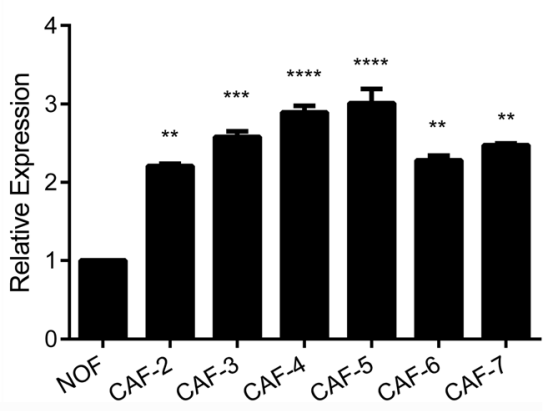

$\mathrm{F} \quad \mathrm{STC2}$

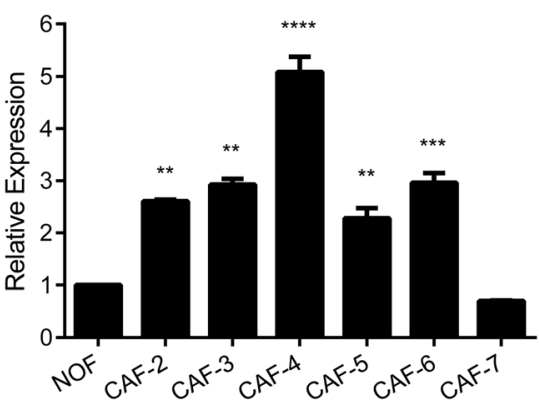

( $p=0.02$, Fig. 8). Similarly, patients with tumors showing negative/scanty presence of CAFs had longer disease-free survival than those with tumor showing abundant presence, in both overall $(p=0.03)$ and invasive front $(p=0.01)$ areas (Fig. 8).

The adjusted multivariate analysis based on Cox proportional regression found that expression of PINP by the stromal cells at the invasive front was a significant predictor of disease-specific and disease-free survival of patients with OSCC (Table 4). Hazard ratios (HRs) of $3.31(95 \% \mathrm{CI}$ $1.54-5.96, p=0.002)$ for specific survival and $3.78(95 \% \mathrm{CI}$ $1.22-11.67, p=0.02)$ for disease-free survival were observed. Presence of CAFs significantly influenced relapse (diseasefree survival) of OSCC patients. For overall distribution of
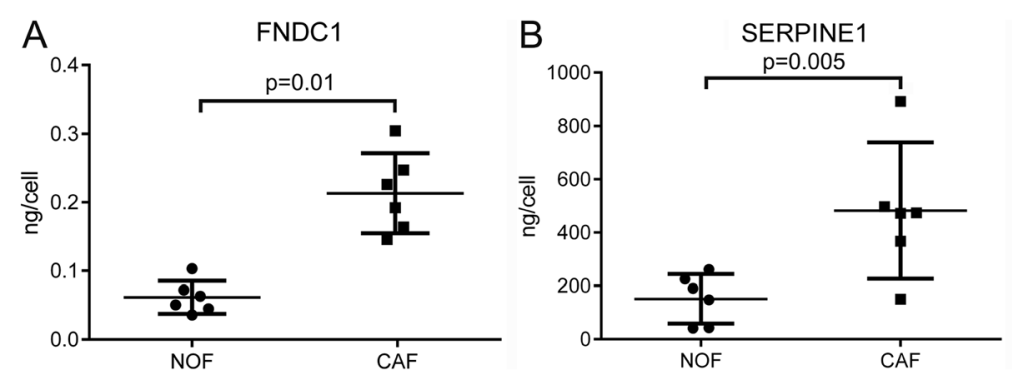

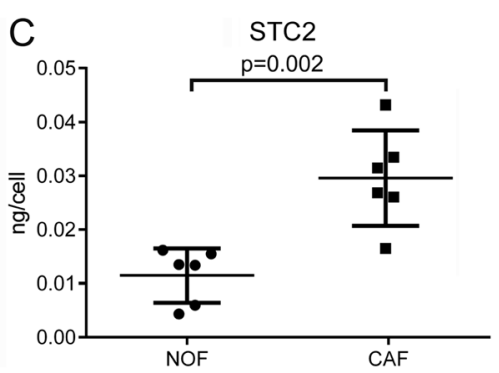

SERPINE1, and STC2. Data are expressed as nanograms of protein/ cell. The amount of FNDC1, SERPINE1, and STC2 produced by CAF cells was significantly higher than NOF cells
Fig. 4 Validation of the higher levels of FNDC1, SERPINE1, and STC2 in $\mathrm{CAF}$ cell lines. Proteins secreted by NOFs and CAFs were collected and subjected to ELISA using specific antibodies against FNDC1, 

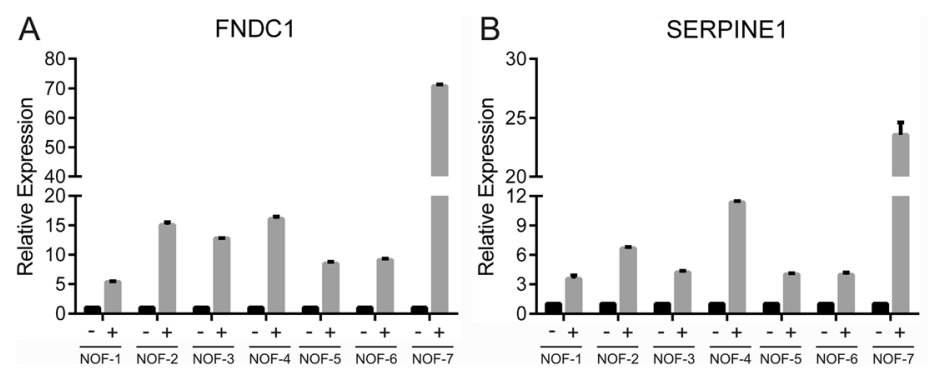

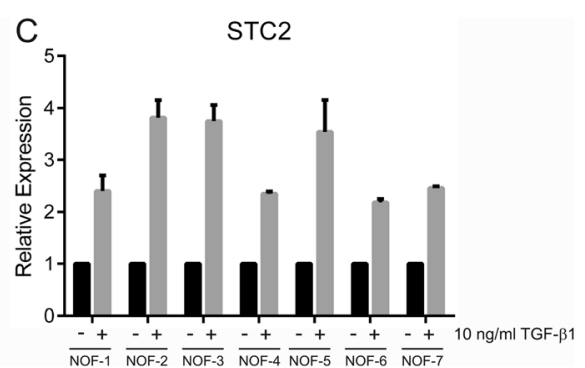

Fig. 5 TGF- $\beta 1$-induced $C A F$ activation is associated with the production of higher levels of FNDC1, SERPINE1, and STC2. NOF cells were cultured in the presence of $10 \mathrm{ng} / \mathrm{ml}$ of TGF- $\beta 1$ for $48 \mathrm{~h}$. Following treatment, cells were collected and subjected to total RNA isolation and quantitative PCR. CAFs induced with $10 \mathrm{ng} / \mathrm{ml}$ of TGF$\beta 1$ showed a marked increase in the expression of FNDC1, SERPINE1, and STC2 compared to untreated control cells
CAFs, a HR of 2.99 (95\% CI 1.52-5.92, $p=0.002)$ was found for abundant presence in relation to negative/scanty presence. Similarly, abundant presence of CAFs in the invasive front revealed a HR of 3.08 (95\% CI 1.61-5.92, $p=0.0001)$. Cox analysis of specific survival also revealed that $\mathrm{N}$ stage is an independent prognostic factor of this OSCC cohort.

\section{Discussion}

Stromal cells in the tumor microenvironment, including lymphocytes, macrophages, endothelial cells, and active fibroblasts, have been shown to influence the aggressiveness of cancer cells by inducing invasion and metastasis [4]. This functional state of tumor-associated cells holds a wealth of prognostic and response-predictive information and opens up novel options for stroma-based anticancer therapies. CAFs, which indicate myofibroblast transdifferentiation, seem to be especially critical for many aspects of oral carcinogenesis, since the presence of CAFs, mainly in the invasive front, denotes a more aggressive phenotype by promoting the proliferation and invasion of tumor cells [8, 11, 27]. However, efforts to develop new treatments targeting CAFs are complicated by our poor understanding of the mechanisms underlying their development and by only partial knowledge of their

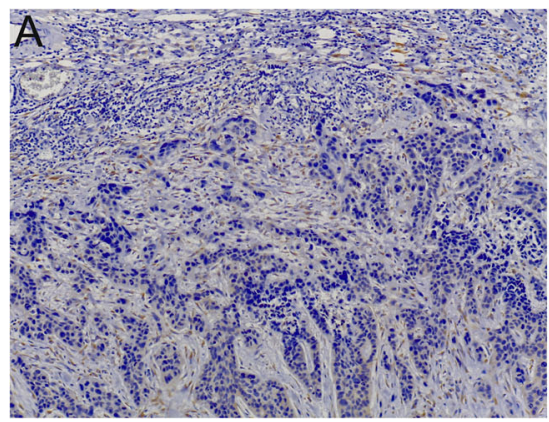

Fig. 6 Immunohistochemical expression of PINP and $\alpha$-SMA in representative samples of OSCCs of this study. a Positivity for PINP was observed mainly in the cytoplasm of the stromal cells adjacent the tumor and in some tumor cells. b $\alpha$-SMA expression was limited to stromal cells, and $\alpha$-SMA-positive cells were concentrated at the tumor mechanisms of induction of OSCCs. Thus, knowledge of CAF secretome signatures may help determine the contribution of this specific cell type to the complex profile of OSCCs. Herein, we analyzed the LFQ proteomic data and identified the secretome signatures of OSCC-derived CAFs. In this way, we were able to characterize the functional state of CAFs and to identify proteins that may be related to the supportive effects of CAFs in tumor cell invasion and metastasis.

CAFs may exchange cytokines, extracellular matrix proteins, and enzymes that promote growth directly through the stimulation of proliferation and survival, as well as invasion via local proteolysis of the extracellular matrix [7, 28]. In fact, we identified several proteins related to extracellular matrix, and the GO terms extracellular matrix organization, extracellular matrix disassembly, and collagen metabolic process were overrepresented in the secretome of CAFs in comparison with NOFs. Among the proteins upregulated in CAFs and associated with these biological processes are FNDC1, SERPINE1, and STC2. Those three proteins were validated by qPCR and ELISA in different CAF cell lines and in the model characterized by TGF- $\beta 1$ stimulating normal fibroblast transition to CAFs.

Recently, attention has been paid to the fibronectin type III domain-containing proteins, but our understanding of their roles in normal and pathological conditions is limited. These proteins

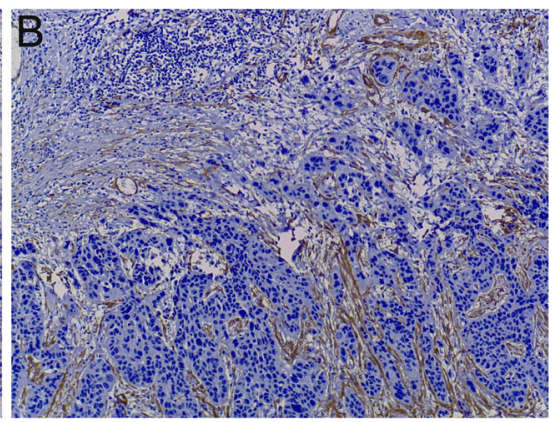

margin, immediately adjacent to the islands of tumor cells and demarcating the invasive front of the tumor. Expression of PINP was mainly detected in the stromal cells which were $\alpha$-SMA-positive cells $(\mathrm{CAFs})$ (original magnification $\times 200$ ) 
Table 2 Correlation analysis of CAF density and PINP expression in the different compartments of the tumor

\begin{tabular}{lllll}
\hline & PINP_overall & $\begin{array}{l}\text { PINP_tumor } \\
\text { front }\end{array}$ & $\begin{array}{l}\text { CAF } \\
\text { density_overall }\end{array}$ & $\begin{array}{l}\text { CAF density_tumor } \\
\text { front }\end{array}$ \\
\hline PINP_overall & - & 0.357 & 0.177 & 0.168 \\
PINP_tumor front & 0.001 & - & 0.128 & 0.538 \\
CAF density_overall & 0.07 & 0.19 & - & 0.777 \\
CAF density_tumor front & 0.08 & 0.0002 & $<0.0001$ & - \\
\hline
\end{tabular}

Spearman's coefficient $\left(r_{\mathrm{s}}\right)$ is above the diagonal, and $p$ value is below diagonal form a block containing the fibronectin III domain, which is characterized by approximately 90 amino acids but with only $15-20 \%$ sequence identity. In spite of this limited identity, all fibronectin III domains have an identical protein fold, represented by a small globule with three $\beta$-strands on one side and four on the other. This fold is similar to that of the immunoglobulin domain, but one strand is switched to the opposite side [29]. Proteins containing this domain are thought to function as transmembrane receptors or cell adhesion molecules, and they can also influence development [30]. FNDC5 (irisin), the fifth member of the fibronectin type III domain-containing protein family, is released into the plasma by skeletal muscles during exercise training [30] and circulated to fat tissues where it induces a transition to brown fat [29], suggesting an important role in glucose metabolism. In primary central nervous system lymphoma, FNDC1 was deleted in $41.7 \%$ of cases and downregulation of the mRNA levels was consistently observed. However, FNDC1 levels were not correlated with the outcome of this tumor [31]. Although FNDC1 was upregulated in all CAF cell lines and TGF- $\beta 1$ inducing CAF activation was followed by increased FNDC1 expression, further analyses in human specimens in association with pathway characterization are required.
SERPINE1 is a multifaceted proteolytic factor that not only functions as an inhibitor of proteases, particularly of serine protease urokinase plasminogen activator (uPA), but also plays an important role in signal transduction [32]. High levels of SERPINE1 have been consistently associated with tumor aggressiveness and poor patient's outcome [33-35]. Besides its prognostic value, SERPINE1 expression has been validated as a marker for therapy in patients with node-negative breast cancer $[36,37]$. Possible mechanisms by which SERPINE1 contributes to cancer dissemination include the prevention of excessive degradation of the extracellular matrix, modulation of cell adhesion, and stimulation of angiogenesis and cell proliferation [38-40]. Immunohistochemical analysis revealed that both SERPINE1 and $\alpha$-SMA at the tumor-advancing front of OSCCs were significantly associated with extracapsular spread of cervical lymph nodes, a prognostic marker of OSCC outcome, and the combination of $\alpha$-SMA/SERPINE1 positivity was significantly associated with poor survival of OSCC patients [41]. Interestingly, C-188-9, a STAT-3 inhibitor, decreased pulmonary fibrosis and resulted in inhibition of fibroblast-to-myofibroblast differentiation and TGF- $\beta$-induced expression of multiple genes including SERPINE1 [42].
Table 3 Spearman correlation of the clinicopathological variables with immunohistochemical expression of PINP and CAF density

\begin{tabular}{llllll}
\hline Variables & \multicolumn{2}{l}{ PINP level } & & & \multicolumn{2}{l}{ CAF density } & \\
\cline { 2 - 3 } \cline { 5 - 6 } & $\begin{array}{l}\text { Overall } \\
\left(r_{\mathrm{s}} / p \text { value }\right)\end{array}$ & $\begin{array}{l}\text { Tumor front } \\
\left(r_{\mathrm{s}} / p \text { value }\right)\end{array}$ & & $\begin{array}{l}\text { Overall } \\
\left(r_{\mathrm{s}} / p \text { value }\right)\end{array}$ & $\begin{array}{l}\text { Tumor front } \\
\left(r_{\mathrm{s}} / p \text { value }\right)\end{array}$ \\
\hline Age & $0.285 / 0.002$ & $0.071 / 0.45$ & & $0.021 / 0.84$ & $0.032 / 0.76$ \\
Gender & $0.027 / 0.78$ & $0.097 / 0.31$ & & $-0.083 / 0.40$ & $-0.141 / 0.15$ \\
Smoking habit & $-0.093 / 0.37$ & $-0.093 / 0.38$ & & $-0.123 / 0.26$ & $-0.011 / 0.91$ \\
Drinking habit & $-0.015 / 0.89$ & $-0.005 / 0.96$ & & $0.038 / 0.74$ & $0.117 / 0.32$ \\
Tumor site & $0.055 / 0.56$ & $0.051 / 0.60$ & & $-0.027 / 0.78$ & $0.025 / 0.79$ \\
T stage & $0.107 / 0.26$ & $-0.021 / 0.82$ & & $0.169 / 0.08$ & $0.125 / 0.20$ \\
N stage & $0.107 / 0.26$ & $-0.071 / 0.45$ & & $0.169 / 0.08$ & $0.178 / 0.07$ \\
Treatment & $0.015 / 0.87$ & $-0.078 / 0.41$ & & $0.261 / 0.007$ & $0.286 / 0.003$ \\
Histopathological grade & $0.139 / 0.14$ & $0.139 / 0.14$ & & $0.056 / 0.56$ & $-0.031 / 075$ \\
Margin status & $0.049 / 0.43$ & $-0.002 / 0.98$ & & $-0.074 / 0.45$ & $-0.051 / 0.61$ \\
Local recurrence & $0.104 / 0.27$ & $0.104 / 0.27$ & & $0.182 / 0.06$ & $0.125 / 0.20$ \\
Regional recurrence & $-0.139 / 0.14$ & $-0.083 / 0.38$ & & $0.103 / 0.29$ & $0.137 / 0.16$ \\
Distant recurrence & $-0.135 / 0.15$ & $0.008 / 0.94$ & $0.096 / 0.32$ & $-0.036 / 0.71$ \\
Second primary & $-0.107 / 0.26$ & $-0.021 / 0.82$ & $-0.156 / 0.11$ & $-0.188 / 0.05$ \\
\hline
\end{tabular}


Fig. 7 Specific survival curves of the OSCC patients according to PINP expression levels and CAF density. Specific survival was determined by the period between the treatment beginning until death by the cancer or last followup information. The univariate analysis revealed that high positivity for PINP in the stromal cells in both overall and tumor invasive front is significantly associated with shortened survival. The specific survival according to the Kaplan-Meier method also revealed that abundant presence of CAFs in the invasive tumor front is associated with poor prognosis
Specific Survival
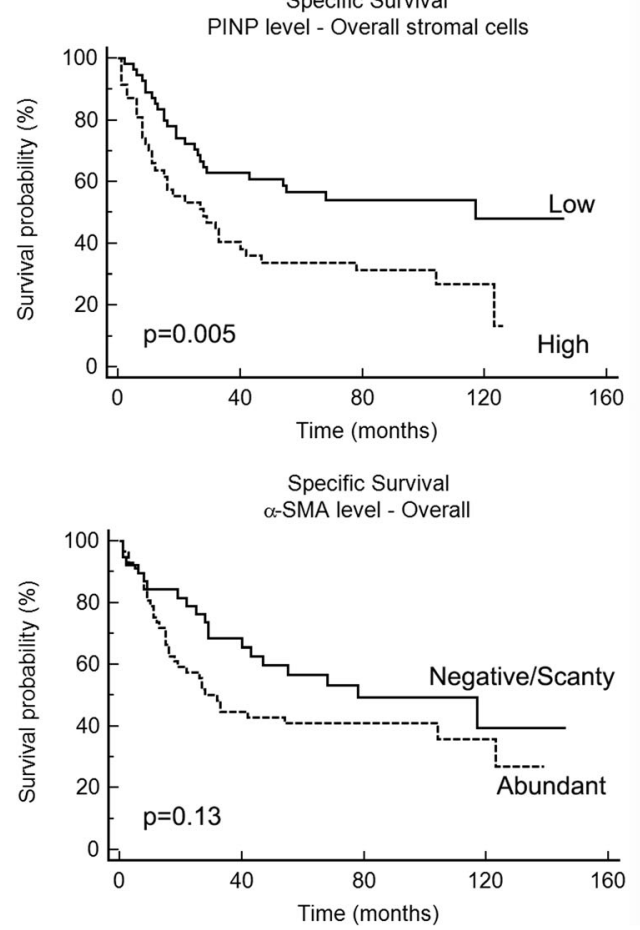

Specific Survival

PINP level - Stromal cells in the front
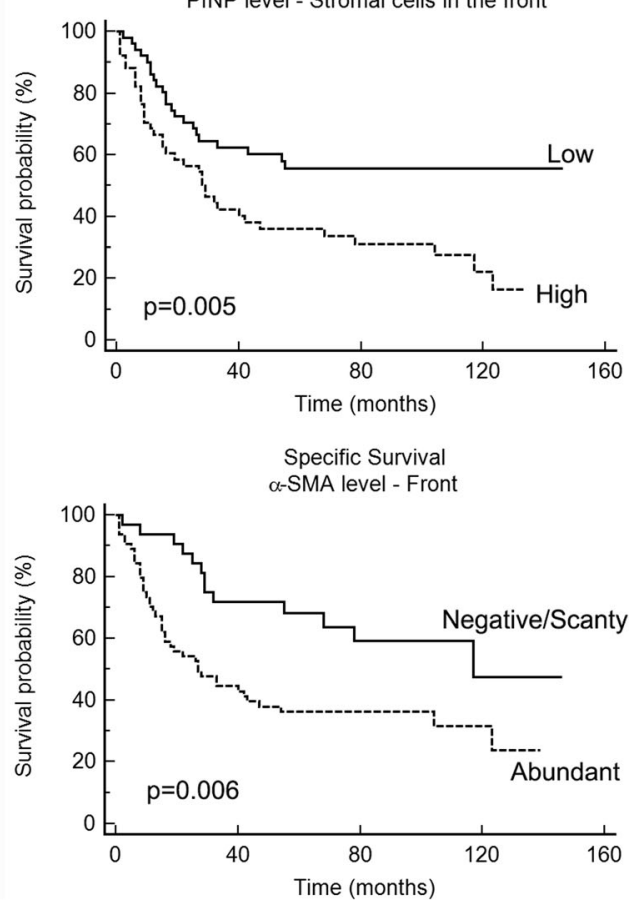

Another protein that may support the protumoral effects of CAFs on oral cancer cells is STC2, which we found to be upregulated in the secretome of CAFs and in TGF- $\beta 1$ treated NOFs. STC2, a secreted glycoprotein hormone expressed by a variety of tissues, regulates calcium and phosphate homeostasis, inhibits apoptosis and oxidative damage, and induces proliferation [43, 44]. STC2 has recently been described to inhibit epithelial-mesenchymal transition through the PKC/claudin-1-mediated signaling in human breast cancer cells [45]. Previous studies have shown deregulated expression of STC2 in a variety of cancers, with its expression correlating with poor prognosis [45-51]. Although such studies
Fig. 8 Expression of PINP and density of CAFs are associated with shortened disease-free survival of patients with OSCC. Disease-free survival was calculated by the time between initiation of treatment until diagnosis of the recurrence (local, regional, or distant) or last followup information for those without recurrence. Abundant presence of CAFs in both overall stroma and invasive tumor front was associated with shortened disease-free survival. Increased PINP expression in the invasive front was also significantly associated with lower disease-free survival
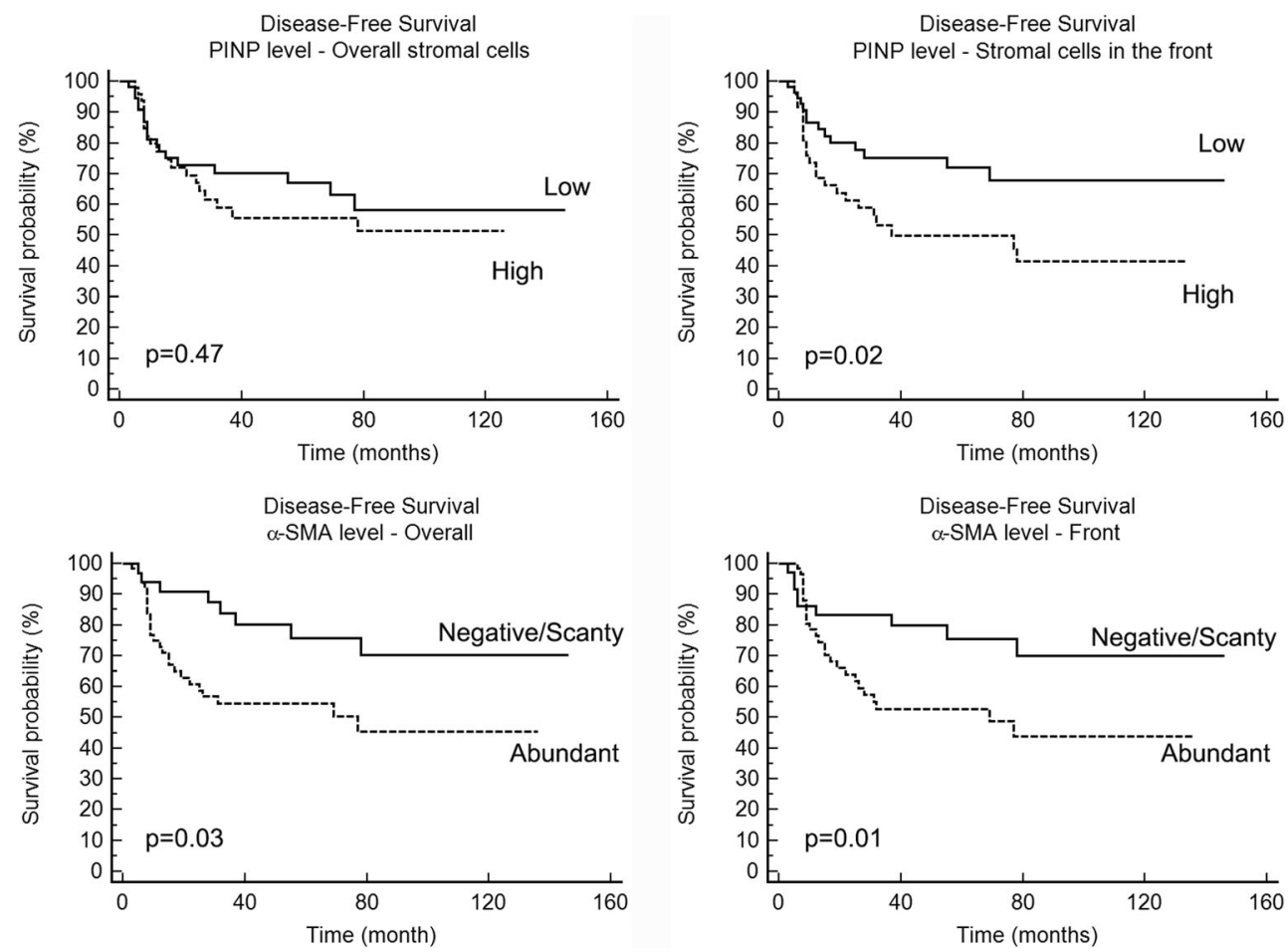
Table 4 Cox multivariate analysis for the risk of death and recurrence

\begin{tabular}{|c|c|c|c|c|}
\hline \multirow[t]{2}{*}{ Parameter } & \multicolumn{2}{|l|}{ Specific survival } & \multicolumn{2}{|l|}{ Disease-free survival } \\
\hline & $\mathrm{HR}(95 \% \mathrm{CI})$ & $p$ Value & $\mathrm{HR}(95 \% \mathrm{CI})$ & $p$ Value \\
\hline \multicolumn{5}{|l|}{$\mathrm{N}$ stage } \\
\hline No & Reference & & & \\
\hline $\mathrm{N}+$ & $2.25(1.03-4.91)$ & 0.04 & & \\
\hline \multicolumn{5}{|c|}{ PINP level—tumor front } \\
\hline Low & Reference & & Reference & \\
\hline High & $3.31(1.54-5.91)$ & 0.002 & $3.78(1.22-11.67)$ & 0.02 \\
\hline \multicolumn{5}{|c|}{ CAF density—overall } \\
\hline Negative/scanty & & & Reference & \\
\hline Abundant & & & $2.99(1.52-5.92)$ & 0.002 \\
\hline \multicolumn{5}{|c|}{ CAF density — tumor front } \\
\hline Negative/scanty & & & Reference & \\
\hline Abundant & & & $3.08(1.61-5.92)$ & 0.0001 \\
\hline
\end{tabular}

have focused on STC2 expression by the tumor cells, the immunohistochemical images clearly show that STC2 is also expressed by mesenchymal cells adjacent to tumor islands resembling CAFs. STC2 may thus be released by CAFs, allowing the OSCC cells to become invasive and prometastatic.

The results presented here also revealed that CAFs express a variety of upregulated proteins that control collagen metabolic processes. This was previously described in other studies that investigated CAFs derived from other tumors [18, 19, 22, 52]. In a recent study, Rasanen and collaborators [20] characterized the secretomes of E-cadherin low mesenchymal-like subpopulations of OSCCs, which resembled that of CAFs, and revealed upregulation of several proteins involved in organization of the extracellular matrix, such as multiple types of collagen. The CAF secretome, particularly type I collagen and its bioactive peptides derived from procollagen maturation, has been associated with an invasion-permissive stroma in ovarian, colon, and breast cancer cells [53] as well as proangiogenic stroma [28, 54]. Interestingly, the decrease in type I collagen expression in breast carcinoma contributes to normalization of the tumor stroma and improves the intratumoral penetration of therapeutics [55]. PINP immunohistochemical analysis, representing the procollagen fragment of type I collagen, revealed positivity in both stromal and tumor cells, but the intensity was lower in tumor cells compared to stromal cells. Strong and positive correlations between PINP expression by stromal cells and CAFs ( $\alpha$-SMApositive cells) were observed. Furthermore, PINP expression by stromal cells in the invasive front was significantly associated with the outcome of patients with OSCCs. The association of abundant presence of CAFs in the invasive tumor front with shorter overall survival was confirmed, as originally described by us [11] and later by others [12-15]. Taken together, our results demonstrate that expression of type I collagen by
CAFs is an indicator of outcome of OSCCs and reinforce the suggested role of CAFs in tumor progression and metastasis.

In conclusion, cancer progression is the result of a complex cross talk between tumor and stromal cells such as CAFs, and an understanding of the mechanisms by which CAFs induce tumorigenesis is essential for identification of new therapeutic targets, as well as novel prognostic markers. In the current study, the secretome profiling of CAFs isolated from OSCC stroma revealed that the expression of proteins involved in extracellular matrix organization and remodeling is altered compared to NOFs, suggesting a possible influence in OSCC phenotypes. FNDC1, SERPINE1, and STC2 may be important proteins associated with CAF-induced oral cancer progression and development, although further research is warranted. Moreover, induction of collagen synthesis by CAFs, particularly type I collagen, may affect OSCC behavior, since high levels of PINP expression by CAFs in the invasive front were significantly associated with a worse prognosis.

Acknowledgments This work was supported by grants from Fundação de Amparo a Pesquisa do Estado de São Paulo-FAPESP, São Paulo, Brazil; Conselho Nacional de Desenvolvimento Científico e Tecnológico-CNPq, Brasília, Brazil, and Coordenação de Aperfeiçoamento de Pessoal de Nível Superior-CAPES, Brasília, Brazil (AUXPE-PVES-570/2013).

\section{Compliance with ethical standard}

Conflicts of interest None

\section{References}

1. Ferlay J, Soerjomataram I, Dikshit R, Eser S, Mathers C, Rebelo M, et al. Cancer incidence and mortality worldwide: sources, methods 
and major patterns in GLOBOCAN 2012. Int J Cancer. 2015;136: E359-86.

2. Warnakulasuriya S. Living with oral cancer: epidemiology with particular reference to prevalence and life-style changes that influence survival. Oral Oncol. 2010;46:407-10.

3. Shah FD, Begum R, Vajaria BN, Patel KR, Patel JB, Shukla SN, et al. A review on salivary genomics and proteomics biomarkers in oral cancer. Indian J Clin Biochem. 2011;26:326-34.

4. Hanahan D, Coussens LM. Accessories to the crime: functions of cells recruited to the tumor microenvironment. Cancer Cell. 2012;21:309-22.

5. Koontongkaew $\mathrm{S}$. The tumor microenvironment contribution to development, growth, invasion and metastasis of head and neck squamous cell carcinomas. J Cancer. 2013;4:66-83.

6. Curry JM, Sprandio J, Cognetti D, Luginbuhl A, Bar-ad V, Pribitkin E, et al. Tumor microenvironment in head and neck squamous cell carcinoma. Semin Oncol. 2014;41:217-34.

7. Gandellini P, Andriani F, Merlino G, D’Aiuto F, Roz L, Callari M. Complexity in the tumour microenvironment: cancer associated fibroblast gene expression patterns identify both common and unique features of tumour-stroma crosstalk across cancer types. Semin Cancer Biol. 2015.

8. Sobral LM, Bufalino A, Lopes MA, Graner E, Salo T, Coletta RD. Myofibroblasts in the stroma of oral cancer promote tumorigenesis via secretion of activin A. Oral Oncol. 2011;47:840-6.

9. Hinsley EE, Kumar S, Hunter KD, Whawell SA, Lambert DW. Endothelin-1 stimulates oral fibroblasts to promote oral cancer invasion. Life Sci. 2012;91:557-61.

10. Tommelein J, Verset L, Boterberg T, Demetter P, Bracke M, De Wever O. Cancer-associated fibroblasts connect metastasispromoting communication in colorectal cancer. Front Oncol. 2015;5:63.

11. Kellermann MG, Sobral LM, da Silva SD, Zecchin KG, Graner E, Lopes MA, et al. Myofibroblasts in the stroma of oral squamous cell carcinoma are associated with poor prognosis. Histopathology. 2007;51:849-53.

12. Kawashiri S, Tanaka A, Noguchi N, Hase T, Nakaya H, Ohara T, et al. Significance of stromal desmoplasia and myofibroblast appearance at the invasive front in squamous cell carcinoma of the oral cavity. Head Neck. 2009;31:1346-53.

13. Vered M, Dobriyan A, Dayan D, Yahalom R, Talmi YP, Bedrin L, et al. Tumor-host histopathologic variables, stromal myofibroblasts and risk score, are significantly associated with recurrent disease in tongue cancer. Cancer Sci. 2010;101:274-80.

14. Bello IO, Vered M, Dayan D, Dobriyan A, Yahalom R, Alanen K, et al. Cancer-associated fibroblasts, a parameter of the tumor microenvironment, overcomes carcinoma-associated parameters in the prognosis of patients with mobile tongue cancer. Oral Oncol. 2011;47:33-8.

15. Marsh D, Suchak K, Moutasim KA, Vallath S, Hopper C, Jerjes W, et al. Stromal features are predictive of disease mortality in oral cancer patients. J Pathol. 2011;223:470-81.

16. Fujii N, Shomori K, Shiomi T, Nakabayashi M, Takeda C, Ryoke $\mathrm{K}$, et al. Cancer-associated fibroblasts and CD163-positive macrophages in oral squamous cell carcinoma: their clinicopathological and prognostic significance. J Oral Pathol Med. 2012;41:444-51.

17. Ding L, Zhang Z, Shang D, Cheng J, Yuan H, Wu Y, et al. $\alpha$ Smooth muscle actin-positive myofibroblasts, in association with epithelial-mesenchymal transition and lymphogenesis, is a critical prognostic parameter in patients with oral tongue squamous cell carcinoma. J Oral Pathol Med. 2014;43:335-43.

18. De Boeck A, Hendrix A, Maynard D, Van Bockstal M, Daniëls A, Pauwels P, et al. Differential secretome analysis of cancerassociated fibroblasts and bone marrow-derived precursors to identify microenvironmental regulators of colon cancer progression. Proteomics. 2013;13:379-88.
19. Chen SX, Xu XE, Wang XQ, Cui SJ, Xu LL, Jiang YH, et al. Identification of colonic fibroblast secretomes reveals secretory factors regulating colon cancer cell proliferation. J Proteomics. 2014;110:155-71.

20. Rasanen K, Sriswasdi S, Valiga A, Tang HY, Zhang G, Perego M, et al. Comparative secretome analysis of epithelial and mesenchymal subpopulations of head and neck squamous cell carcinoma identifies S100A4 as a potential therapeutic target. Mol Cell Proteomics. 2013;12:3778-92.

21. Ge S, Mao Y, Yi Y, Xie D, Chen Z, Xiao Z. Comparative proteomic analysis of secreted proteins from nasopharyngeal carcinomaassociated stromal fibroblasts and normal fibroblasts. Exp Ther Med. 2012;3:857-60.

22. Salo S, Bitu C, Merkku K, Nyberg P, Bello IO, Vuoristo J, et al. Human bone marrow mesenchymal stem cells induce collagen production and tongue cancer invasion. PLoS One. 2013;8:e77692.

23. Sobral LM, Zecchin KG, de Nascimento Aquino S, Lopes MA, Graner E, Coletta RD. Isolation and characterization of myofibroblast cell lines from oral squamous cell carcinoma. Oncol Rep. 2011;25:1013-20.

24. Sobral LM, Montan PF, Zecchin KG, Martelli-Junior H, Vargas PA, Graner E, et al. Smad7 blocks transforming growth factor- $\beta 1$ induced gingival fibroblast-myofibroblast transition via inhibitory regulation of Smad2 and connective tissue growth factor. J Periodontol. 2011;82:642-51.

25. Sawazaki-Calone I, Rangel A, Bueno AG, Morais CF, Nagai HM, Kunz RP, et al. The prognostic value of histopathological grading systems in oral squamous cell carcinomas. Oral Dis. 2015;21:75561.

26. Risteli L, Risteli J. Biochemical markers of bone metabolism. Ann Med. 1993;25:385-93.

27. Kellermann MG, Sobral LM, da Silva SD, Zecchin KG, Graner E, Lopes MA, et al. Mutual paracrine effects of oral squamous cell carcinoma cells and normal oral fibroblasts: induction of fibroblast to myofibroblast transdifferentiation and modulation of tumor cell proliferation. Oral Oncol. 2008;44:509-17.

28. Han Y, Zhang Y, Jia T, Sun Y. Molecular mechanism underlying the tumor-promoting functions of carcinoma-associated fibroblasts. Tumour Biol. 2015;36:1385-94.

29. Erickson HP. Irisin and FNDC5 in retrospect: an exercise hormone or a transmembrane receptor? Adipocyte. 2013;2:289-93.

30. Fain JN, Company JM, Booth FW, Laughlin MH, Padilla J, Jenkins NT, et al. Exercise training does not increase muscle FNDC5 protein or mRNA expression in pigs. Metabolism. 2013;62:1503-11.

31. Sung CO, Kim SC, Karnan S, Karube K, Shin HJ, Nam DH, et al. Genomic profiling combined with gene expression profiling in primary central nervous system lymphoma. Blood. 2011;117:1291300 .

32. Itoh T, Hayashi Y, Kanamaru T, Morita Y, Suzuki S, Wang W, et al. Clinical significance of urokinase-type plasminogen activator activity in hepatocellular carcinoma. J Gastroenterol Hepatol. 2000;15: 422-30.

33. Zheng Q, Tang ZY, Xue Q, Shi DR, Song HY, Tang HB. Invasion and metastasis of hepatocellular carcinoma in relation to urokinasetype plasminogen activator, its receptor and inhibitor. J Cancer Res Clin Oncol. 2000;126:641-6.

34. Schmitt M, Harbeck N, Brünner N, Jänicke F, Meisner C, Mühlenweg B, et al. Cancer therapy trials employing level-ofevidence-1 disease forecast cancer biomarkers uPA and its inhibitor PAI-1. Expert Rev Mol Diagn. 2011;11:617-34.

35. Duffy MJ, McGowan PM, Harbeck N, Thomssen C, Schmitt M. UPA and PAI-1 as biomarkers in breast cancer: validated for clinical use in level-of-evidence-1 studies. Breast Cancer Res. 2014;16:428.

36. Look MP, van Putten WL, Duffy MJ, Harbeck N, Christensen IJ, Thomssen C, et al. Pooled analysis of prognostic impact of 
urokinase-type plasminogen activator and its inhibitor PAI-1 in 8377 breast cancer patients. J Natl Cancer Inst. 2002;94:116-28.

37. Harris L, Fritsche H, Mennel R, Norton L, Ravdin P, Taube S, et al. American society of clinical oncology update of recommendations for the use of tumor markers in breast cancer. J Clin Oncol. 2007; 25:5287-312.

38. Roca C, Primo L, Valdembri D, Cividalli A, Declerck P, Carmeliet $\mathrm{P}$, et al. Hyperthermia inhibits angiogenesis by a plasminogen activator inhibitor 1-dependent mechanism. Cancer Res. 2003;63: 1500-7.

39. Bajou K, Masson V, Gerard RD, Schmitt PM, Albert V, Praus M, et al. The plasminogen activator inhibitor PAI- 1 controls in vivo tumor vascularization by interaction with proteases, not vitronectin. Implications for antiangiogenic strategies. J Cell Biol. 2001;152: 777-84.

40. Czekay RP, Loskutoff DJ. Plasminogen activator inhibitors regulate cell adhesion through a uPAR-dependent mechanism. J Cell Physiol. 2009;220:655-63.

41. Dhanda J, Triantafyllou A, Liloglou T, Kalirai H, Lloyd B, Hanlon $\mathrm{R}$, et al. SERPINE1 and SMA expression at the invasive front predict extracapsular spread and survival in oral squamous cell carcinoma. Br J Cancer. 2014;111:2114-21.

42. Pedroza M, Le TT, Lewis K, Karmouty-Quintana H, To S, George AT, et al. STAT-3 contributes to pulmonary fibrosis through epithelial injury and fibroblast-myofibroblast differentiation. FASEB J. 2015 Aug 31.

43. Na SS, Aldonza MB, Sung HJ, Kim YI, Son YS, Cho S, et al. Stanniocalcin-2 (STC2): a potential lung cancer biomarker promotes lung cancer metastasis and progression. Biochim Biophys Acta. 1854;2015:668-76.

44. Wang Y, Gao Y, Cheng H, Yang G, Tan W. Stanniocalcin 2 promotes cell proliferation and cisplatin resistance in cervical cancer. Biochem Biophys Res Commun. 2015;466:362-8.

45. Hou J, Wang Z, Xu H, Yang L, Yu X, Yang Z, et al. Stanniocalicin 2 suppresses breast cancer cell migration and invasion via the $\mathrm{PKC} /$ claudin-1-mediated signaling. PLoS One. 2015;10:e0122179.
46. Bouras T, Southey MC, Chang AC, Reddel RR, Willhite D, Glynne $\mathrm{R}$, et al. Stanniocalcin 2 is an estrogen-responsive gene coexpressed with the estrogen receptor in human breast cancer. Cancer Res. 2002;62:1289-95.

47. Ieta K, Tanaka F, Yokobori T, Kita Y, Haraguchi N, Mimori K, et al. Clinicopathological significance of stanniocalcin 2 gene expression in colorectal cancer. Int J Cancer. 2009;125:926-31.

48. Tamura K, Furihata M, Chung SY, Uemura M, Yoshioka H, Iiyama $\mathrm{T}$, et al. Stanniocalcin 2 overexpression in castration-resistant prostate cancer and aggressive prostate cancer. Cancer Sci. 2009;100: 914-9.

49. Law AY, Lai KP, Ip CK, Wong AS, Wagner GF, Wong CK. Epigenetic and HIF-1 regulation of stanniocalcin-2 expression in human cancer cells. Exp Cell Res. 2008;314:1823-30.

50. Law AY, Wong CK. Stanniocalcin-2 is a HIF-1 target gene that promotes cell proliferation in hypoxia. Exp Cell Res. 2010;316: 466-76.

51. Chang AC, Jellinek DA, Reddel RR. Mammalian stanniocalcins and cancer. Endocrinol Relat Cancer. 2003;10:359-73.

52. Van Bockstal M, Lambein K, Van Gele M, De Vlieghere E, Limame R, Braems G, et al. Differential regulation of extracellular matrix protein expression in carcinoma-associated fibroblasts by TGF- $\beta 1$ regulates cancer cell spreading but not adhesion. Oncoscience. 2014;1:634-48.

53. Kenny HA, Krausz T, Yamada SD, Lengyel E. Use of a novel 3D culture model to elucidate the role of mesothelial cells, fibroblasts and extra-cellular matrices on adhesion and invasion of ovarian cancer cells to the omentum. Int J Cancer. 2007;121:1463-72.

54. Tang D, Gao J, Wang S, Ye N, Chong Y, Huang Y, et al. Cancerassociated fibroblasts promote angiogenesis in gastric cancer through galectin-1 expression. Tumour Biol. 2015. doi:10.1007/ s13277-015-3942-9.

55. Liu J, Liao S, Diop-Frimpong B, Chen W, Goel S, Naxerova K, et al. TGF- $\beta$ blockade improves the distribution and efficacy of therapeutics in breast carcinoma by normalizing the tumor stroma. Proc Natl Acad Sci U S A. 2012;109:16618-23. 